It is understood that these tables are to be legalised for use in Great Britain. They should prove very helpful both in England during the summer months and throughout the year in those countries where the minimum temperature approximates more closely to $80^{\circ} \mathbf{F}$. Proof spirit was legally defined so long ago as 1816, though it was not until 1847 that Joseph Drinkwater determined the relative proportions of alcohol and water in it. The Fahrenheit temperature then selected was $51^{\circ}$, which is proving often to be inconvenient in practice. At the temperature of $80^{\circ} \mathrm{F}$. now chosen, proof spirit has a specific gravity of 0.913162 ; it contains $49 \cdot 28$ per cent of alcohol by weight, or $\mathbf{5 7 \cdot 2 5}$ per cent by volume. Absolute alcohol at this temperature is equivalent to $175 \cdot 35$ per cent of proof spirit.

\section{Harnack House, Berlin-Dahlem}

THE colony which has grown up at Dahlem in the suburbs of Berlin, consisting of the various departments of the Kaiser Wilhelm Gesellschaft, from which researches in all branches of science have added significantly to knowledge, is now a large one. The growth of the purely scientific laboratories has naturally brought with it other needs, for example, suitable lecture and meeting-rooms, a club-house and even residential facilities. These have been provided in the form of Harnack House, named after the first president of the Kaiser Wilhelm Gesellschaft, which is now responsible for no less than thirty research institutes it has called into being. Harnack House is essentially a co-operative concern; the German State provided the money for the building, the Prussian State presented the land, and individuals, industrial associations and public bodies all gave liberal assistance. It consists of large and small public rooms named after celebrities in the sentimental German manner, a canteen and a number of bedrooms. These are in the first place available for foreign men of science who are working at the Institute, and also for other foreign scientific workers of repute who are visiting it or are specially recommended. The terms are moderate and as the journey by the 'underground' takes less than half an hour, residence there for a single night or for a longer period may prove attractive to scientific workers visiting Berlin, particularly as Harnack House is a centre of research activity.

\section{Yellow Sodium Light for Detecting Colourless Details}

Dr. M. Luckiesh and Dr. F. K. Moss, of the Lighting Research Laboratory of the General Electric Company of America, reported at a meeting of the Optical Society of America on October 17 an interesting property of the new sodium vapour lamp which will shortly be upon the market. According to Science Service, they stated that for revealing the details of small colourless objects the yellow single colour light from sodium vapour is definitely and markedly better than the light emitted by ordinary incandescent tungsten filament lamps. In addition to revealing the details of small objects better, the speed of retinal impression is also higher. On the average, the proportion of the light reflected by a large number of coloured specimens is much the same for both illuminants, although there is wide variation for individual colours. Sodium light enhances brightness contrast between various pairs of colours in more cases than tungsten light does, but some of the exceptions are important. To eyes accustomed to white light, the yellow sodium light sometimes produces curious phenomena. Experiments were made to find out if there was a difference in the nervous muscular strain produced by reading under white light and under sodium light respectively, but no difference could be detected in the human eye after subjection to the two illuminants.

\section{Developments in Industrial Research}

MUCH good work is being done in industrial research by the Mellon Institute of Pittsburgh. In the Shoe Factory and in the Starchroom Laundry Journal of October 1933 interesting tests are described on shoe leather and on 'Calgon', a special form of sodium metaphosphate for use in laundering. In introducing a new special leather, it was found necessary to supplement actual wearing trials by laboratory tests. The 'Vici' leather, produced by a new method of tanning, was exposed in an oxygen bomb and in a fadeometer, and it was tested for use as a water bag. But these methods were not sufficient. It was necessary to test the resistance of the leather to 'scuffing', that is, to surface disfigurement by a sharp, cutting blow. Shoes made from various leathers were enclosed in a wooden drum with buttons on the inside. The air in the drum was kept at a temperature of $100^{\circ} \mathrm{F}$. and it was rotated at 18 revolutions per minute. Five sample shoes are placed in the drum with a moist abrasive and the test is completed when the counter shows that 700 revolutions have been made. The samples are then carefully wiped and dried and are graded on the basis of the number, area and depth of the scuffs. This test gave satisfactory results. The story told in the Laundry Journal of the technical development of sodium metaphosphate from being merely a laboratory curiosity to being a valuable commercial product is most interesting. Calgon dissolves soaps in the washer, shortens the time required, is not harmful to the materials or injurious to colours. It has excellent emulsifying properties, as shown by its successful use in the laundering of greasy overalls.

\section{Re-Afforestation in Mexico}

According to a Mail Report from Science Service (Washington, D.C.), Mexico is undertaking a reafforestation programme. It is stated that the Mexican Ministry of Agriculture is now putting into force a programme of reafforestation of areas that have been denuded since the Spanish Conquest, which turned many parts of Mexico into semi-arid regions. "Local detachments of soldiers all over the country have been ordered to co-operate with government agricultural agents in their reforestation work. During the last five years new trees have been planted on many of the naked slopes of the 